\title{
A Conceptual Framework for the Forklift-to-Grid (F2G) Implementation
}

\section{Matjaz Knez, Bojan Rosi}

Faculty of Logistics Celje, University of Maribor, Celje, Slovenia.

Email: matjaz.knez@fl.uni-mb.si

Received May $10^{\text {th }}, 2013$; revised June $10^{\text {th }}, 2013$; accepted June $17^{\text {th }}, 2013$

Copyright (C) 2013 Matjaz Knez, Bojan Rosi. This is an open access article distributed under the Creative Commons Attribution License, which permits unrestricted use, distribution, and reproduction in any medium, provided the original work is properly cited.

\begin{abstract}
This paper focuses on presenting the current research findings on the "Vehicle to Grid" concept and proposes theoretical model of F2G integration in energy management of a warehouse. The study is based on an analysis of collected data and on model calculations of the economic value. Analyses of data, calculations of economic value and profitability of the proposed business model give positive results, which fully confirm the thesis that the integration of renewable energy sources and new modern technologies in the logistic processes can improve energy management.
\end{abstract}

Keywords: Electric Forklift; Energy Management; Technological Concept—“Forklift to Grid”

\section{Introduction}

Energy is an essential element in human life. A secure, sufficient and accessible supply of energy is very crucial for the sustainability of modern societies. The demand for the provision of energy is increasing worldwide and will continue to rise as developing nations reach developed status and maintain their modernisation trends. Most predictions provided that the energy consumption growth of developed nations compound at around $1 \%$ a year; however, for developing nations, consumption presently compound at over $5 \%$ a year [1].

Interruptions of electricity supply at the national level are due to the lack of production as well as the lack of transmission capacity, and have an immediate and significant impact on the industry, households and other household goods [2]. It is therefore necessary to constantly seek new ways of storing electrical energy and thus affect the coverage of energy and peak power system stabilization. One of the options that the more and more often considered great power potential and interesting market opportunity is the innovative technological concept called "Vehicle to Grid" (V2G), designed by the leading researcher and innovator, Professor, Dr. Willett Kempton from the University of Delaware, USA.

The V2G concept is an attractive idea of how to synergize the electricity and the transportation sector. This concept with pure electric and hybrid-electric vehicles (which are capable of connecting to the grid and loading/ unloading electrical energy) could help to better manage electricity resources. Moreover, it enables vehicle owners to earn money by selling power back to the grid when parking, depending on the current fuel- and electricityprices [3].

Within the United States alone [4], there are currently some 230 million gasoline-powered cars, sport utility vehicles (SUVs) and light trucks, which, if converted to or replaced with a combination of plug-in hybrids and all-electric vehicles, could have increased the power capacity of all electricity generation in the country by 20 fold. This large potential power source has great value. When a V2G-enabled vehicle is tied into the electric grid via a power connection, the vehicle's instantly-responsible electric storage system can be directed by a wireless communication device to deliver power services to the region. These power services help to stabilize the electric grid, significantly enhance the capabilities of renewable wind and solar generation, and provide many other value-added services to the community (Figure 1).

V2G further provides an opportunity to improve the reliability of the electric grid. The vehicles are typically parked where people use power-at home and at work. Placement of the vehicles on the grid in this manner makes the power supply a "distributed generation tool" for localized storage and use. When the grid fails, the cars are ready to get back-up the power supply.

Moreover, V2G creates an opportunity for vehicles to 


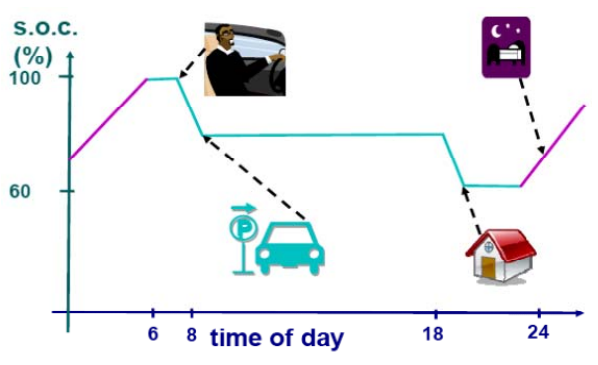

(a)

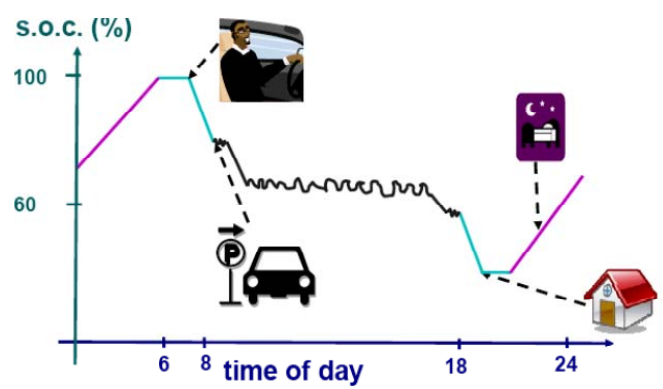

(b)

Source: [5].

Figure 1. (a) The conventional view on the use of electric vehicles; and (b) a new perspective on the use of electric vehicles with V2G concept.

become revenue-producing assets, as opposed to liabilities that lose value year after year. The V2G-equipped vehicles participate in specific power markets in return for a fee. Several variables affect the income potential, including the size of the battery pack, the type of power service, the hours-per-day the car parked and plugged in, and the market rate, or value of the service. Coupling the above opportunities with a cleaner environment and reduced dependence on imported petroleum-based fuels, $\mathrm{V} 2 \mathrm{G}$ is a win-win for everyone [4].

The V2G concept is a way to use electric vehicles (battery, fuel cell or hybrid vehicle) to provide electricity for various purposes while electric vehicles are parked. Each vehicle must meet three requirements, namely [6]:

- The vehicle must be plugged in;

- It must have a system (or communication unit) for communication with the electrical network (distributors);

- An electricity consumption meter must be installed in the vehicle.

Since the object of the recent study is the electric forklift and a new innovative technological concept which derives from the original $\mathrm{V} 2 \mathrm{G}$ concept and the type of electric vehicle, the term F2G is used. The basic idea behind the concept of F2G is to "buy electricity when it is cheap and sell when it is expensive", which means that the vehicle battery charges when the electricity price is low (in low tariff) and sells the energy to the grid when the electricity price is high (in high tariff) [5].

\section{F2G Implementation-A Slovenian Case Study}

The research was performed on a central warehouse with mixed goods owned by the largest Slovenian retailer Mercator d.d. The warehouse is located in the centre of Ljubljana (the capital of Slovenia). The possibilities of building a photovoltaic electric power plant were calculated for the flat roof of the warehouse with size of 600 $\mathrm{m}^{2}$. Calculations were made regarding solar energy use.

Mercator uses 128 electric forklifts with an average battery capacity of $17.2 \mathrm{kWh}$ per vehicle. The forklifts are used for moving goods and other warehouse operations from 6.00 till 22.00, 5 days per week. During weekends and public holidays (114 days a year), vehicles are parked at the chargers. Each vehicle has its own schedule of operations, but on average it is used 11 hours per day. That means that $30 \%$ of the working time vehicles are parked at the chargers.

Forklifts can now use lithium ion batteries to get F2G plug-ins, either as original equipment or as supplementary aftermarket power modules. Lightweight lithium ion batteries have greater power density and are capable of thousands of charge cycles, making them suitable for the grid's fluctuating need for power [7].

The photovoltaic (PV) roof system could feed the grid directly or charge the vehicle batteries. The vehicles could make money selling power into the grid during high-load conditions by responding to market price signals above. The system (smart grid) could monitor vehicle battery charge, solar output and local electric system demand.

With a real-time controller, the system can respond to price signals from the electric grid spot market. When the grid calls for more power, system would feed in the available surplus from the forklift batteries and the PV charging system, thus helping to reduce spot prices and satisfy the system's need for power. A key aspect of achieving the promise of F2G systems and a renewable electric grid is the ability to implement smart control between the electric grid, user devices, and power sources such as F2G batteries and distributed generation such as PV.

There are more possible scenarios [8], but only one is described in this paper, where all energy produced by the PV roof is sold to the grid directly and the forklifts are charged from the grid and sell energy back where there is a need for that.

\section{The Research}

\subsection{Energy from PV}

The data was acquired from the Ministry of the Environment and Spatial Planning and the Environmental Agency of the Republic of Slovenia for the period from 
2003 to 2009 . The measuring spot lies very close to the warehouse. The micro location is significant due to its specific features which are present in this part of the city, e.g. fog and smog. The degree of solar irradiation that reaches Earth depends on solar activities, latitude, weather (cloudiness, humidity) and altitude as well as on the shape of the surface [9]. Slovenia is crossed by the latitude of $46^{\circ}$ north, which influences the angle of solar rays, depending on the season, taking into account the axis of the earth of $23.5^{\circ}$.

The latitude of $46^{\circ}$ reaches the maximum angle on $21^{\text {st }}$ June, which is $67.5^{\circ}\left[90^{\circ}-\left(46^{\circ}-23.5^{\circ}\right)\right]=67.5^{\circ}$. In December, when the days are the shortest, the angle is the smallest. Therefore, the sun reaches the lowest energy values of irradiation, which means that the angle of rays is the smallest on $21^{\text {st }}$ December at noon, when it is only $21.5^{\circ}$. Regardless of the optimal direction of solar cells that alters throughout the year, the data in this study refers to the horizontal surface. With the optimal direction of solar cells which also takes into account the current latitude (based on the horizontal surface) and the direction of the sun, the expected efficiency increases by at least 10 percent.

Slovenia mainly has continental weather and different seasons. Therefore, the total volume of solar energy is smaller than for example in tropical areas and is also unequally distributed throughout the year (Figure 2). In Germany, the irradiation is around $1000 \mathrm{kWh} / \mathrm{m}^{2}$ and in subtropical areas it is around 2000 or $2500 \mathrm{kWh} / \mathrm{m}^{2}$. Slovenia lies ahead of Germany, as it has around 1250 $\mathrm{kW} / \mathrm{m}^{2}$.

The research further aims to calculate solar energy and thus focus on limit values of solar irradiation (minimum and maximum) throughout the entire year. The focus was on year 2009. Moreover, the study further took into account the data for December as the weakest month and July as the strongest month regarding the distribution of solar energy.

The efficiency of solar modules, which are available on the market today, ranges between 8 and 20 percent. This research used the electric characteristics of semicrystal silicon photovoltaic modules produced by the company Bisol d.o.o. from Slovenia, where the average efficiency of cell transformations (at temperatures of $25^{\circ} \mathrm{C}$ and $44^{\circ} \mathrm{C}$ ) is 14 percent.

Figure 3 shows values of produced energy multiplied by the efficiency of the chosen solar cells. These values then represent the electric power that could be used. The values refer to a square meter of horizontal surface.

Mercator has a flat roof of $600 \mathrm{~m}^{2}$, where we collected that data shown in Figure 4.

Figure 4 shows that the average production of solar energy per day in July was $510 \mathrm{kWh}$ and the average solar energy produced in December was $53 \mathrm{kWh}$, which

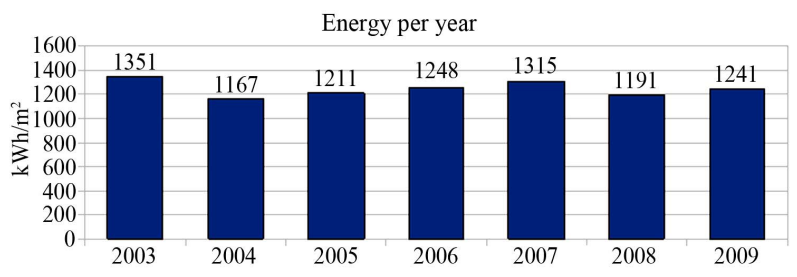

Source: [10].

Figure 2. Summary of energy per year in $\mathrm{kW} / \mathrm{m}^{2}$ on a horizontal surface.

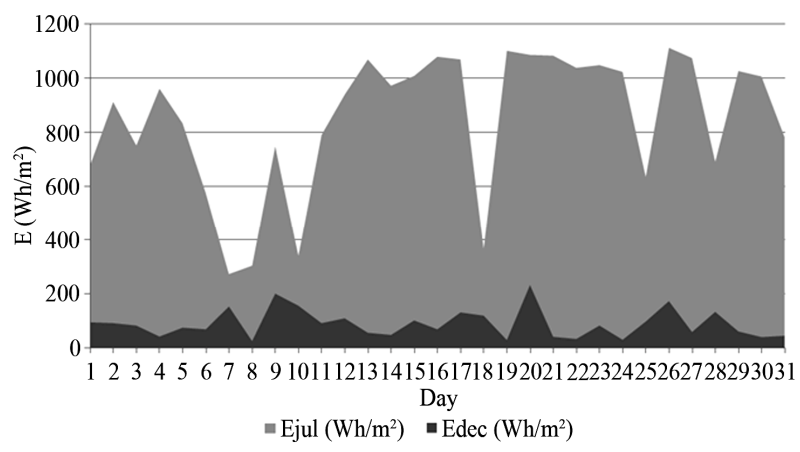

Source: [10].

Figure 3. Energy distribution (per day $/ \mathrm{m}^{2}$ ) in July and December 2009.

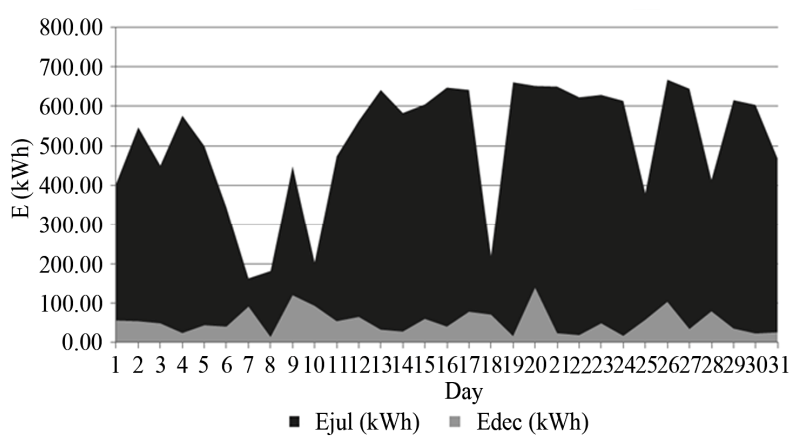

Source: [10].

Figure 4. Energy distribution (per day/roof) in July and December 2009.

shows that if the system would use this energy for warehouse energy needs, the amount of energy produced in July would cover $5 \%$ of the daily energy demand and in December merely $0.6 \%$. But due to the policy of the electrical energy system in Slovenia it is better to sell all the produced energy to the local grid, because the prices are subsidized by the government.

\subsection{Value of F2G Implementation in Warehouse}

The economic viability of F2G critically depends on the cost; the forklift owner has to produce F2G power [3]. The cost for regulation down is zero because regulation down is the same as charging the battery, thus it is "free charging" at times when the vehicle is providing regula- 
tion down. Yearly cost for regulation up is [3]:

$$
C_{\text {reg-up }}=\left(C_{e n} P t_{p l u} g R_{d-c}\right)+a_{c}
$$

where $C_{\text {reg-up }}$ stand for total cost of regulation up, $C_{e n}$ for the cost per energy unit in $€ / \mathrm{kWh}$ and includes the cost of electricity, losses, plus battery degradation costs, and $C_{a c}$ is the annualized capital cost for additional equipment needed for $\mathrm{F} 2 \mathrm{G}$.

Equation (2) is used to calculate the per $\mathrm{kWh}$ cost to the battery of forklift owner for providing power to the grid and Equation (3) is used to calculate the cost of battery degradation.

$$
\begin{gathered}
c_{e n}=\frac{c_{p e}}{\eta_{c o n v}}+c_{d} \\
c_{d}=\frac{c_{b a t}}{L_{E T}}=\frac{\left(E_{s} c_{b}\right)+\left(c_{1} t_{1}\right)}{L_{c} E_{s} D o D}
\end{gathered}
$$

where $c_{p e}$ is the cost of purchased electricity for recharging in $€ / \mathrm{KWh}, c_{d}$ - the cost of battery degradation in $€ / \mathrm{KWh}$ calculated as shown in Equation (3), $\eta_{\text {conv }}$-the conversion efficiency of fuel or electricity (in this case it is the two way electrical efficiency (electricity to battery storage and back to the electricity), which is 0.73 for a battery with above average efficiency, $c_{b a t}$ the battery replacement cost in $€$ (capital and labour costs), LETthe battery lifetime energy throughput for a participant cycling regime in $\mathrm{kWh}, E_{s}$ - the total energy storage of the battery in $\mathrm{kWh}, c_{b}$ - the cost of battery replacement in $€ / \mathrm{kWh}, c_{1}$ - the cost of labour in $€ / \mathrm{h}, t_{1}$-labour time required for battery replacement, and $L_{c}$-is the battery lifetime in cycles.

The other cost component of delivering F2G power is the fixed cost, expressed as annualized capital cost $c_{a c}$ for additional equipment required for F2G (Equation 4) [3].

$$
c_{a c}=c_{c} \times C F R=c_{c} \times \frac{d}{1-(1+d)^{-n}}
$$

where $c_{c}$ is the capital cost (the one time investment) in $€$, $d$ the discount rate and $n$ is the time during which the investment is amortized in years. AC propulsion, Inc. [11] has designed a power electronics system that allows charging from and discharging to the grid, whose fixed cost is around $284 €\left(c_{\text {pes }}\right)$. Further requirements are an on-board meter of electrical flow for billing purposes, which costs around $€ 35\left(c_{m s}\right)$ and a wireless system installed in production scale, which is estimated at around $€ 71\left(c_{w s}\right)$. The total capital cost $\left(c_{c}=c_{p e s}+c_{m s}+c_{w s}\right)$ is $€ 390$. According to Equation (4), the capital annualized cost using a discount rate of $10 \%$ over a period of 10 years is approx. $€ 39$ per year, per forklift.

The electrical power capacity available for V2G is determined by two factors [3]: 1) the limitation of the electrical circuit where the forklift is connected and 2) the stored energy in the battery divided by the time it is used.

The electrical circuit limit is computed from the circuit's ampere capacity (A), multiplied by the circuit's voltage (V). This is the power capacity of the line or $P_{\text {line }}$ Equation (5).

$$
P_{\text {line }}=I \times U=50 \mathrm{~A} \times 220 \mathrm{~V}=11 \mathrm{~kW}
$$

Based on the practical limits of typical home and commercial circuits, the study uses $15 \mathrm{~kW}$ as the $P_{\text {line }}$ limit. The limit imposed on the electrical power capacity for F2G by the forklift ( $\left.P_{\text {forklift }}\right)$ is a function of the energy stored onboard (i.e. in the batteries), the dispatch time needed, and the driver's requirement for driving range. The formula for calculating $P_{\text {forklift }}$ for battery EDVs is shown in Equation (6):

$$
P_{\text {forklift }}=\frac{\left(E_{s} D o D-d_{d}+d_{r b} / \eta_{\text {forklif }} t\right) \eta_{i n v}}{t_{\text {disp }}}
$$

where $P_{v e h}$ is power capacity in $\mathrm{kW}, E_{s}$ the stored energy available in $\mathrm{kWh}, D o D$ the maximum depth of discharge of the battery, usually $80 \%$ for NiMH and $100 \%$ for Li-Ion batteries, $d_{d}$ the distance driven in miles since the battery was full, $\eta_{\text {forklift }}$ the forklift driving efficiency in $\mathrm{km} / \mathrm{kWh}, \eta_{\text {inv }}$ the efficiency of the inverter and other power electronics (dimensionless) with a value of 0.93 [3], and $t_{\text {disp }}$ is the dispatch time in $h$. The dispatch time will be a fraction of the plugged-in time. The electrical power capacity for regulation is determined by the limits imposed by $P_{\text {line }}$ rather than the $P_{\text {veh }}$. When F2G is used for regulation, $P_{\text {veh }}$ is a much higher value than $P_{\text {line }}$ due to the short instantaneous dispatch time (usually on the order of 1 - $4 \mathrm{~min}$ ).

When the vehicle is providing regulation down only (power flowing from grid to vehicle), the power capacity will be defined by wiring and the electronics $\left(P_{\text {line }}\right)$, but the storage capacity of the battery and $D o D$ will determine how long the vehicle will be plugged-in $\left(t_{\text {plug }}\right)$ before the battery is full. Referring to Tomić and Kempton's [3] calculations and equations rearranging the theoretical research we arrive at $t_{\text {plug }}$ Equation (7)

$$
t_{\text {plug }}=\frac{E_{s} D o D \eta_{\text {charger }}}{P_{\text {line }} R_{d-c}}
$$

where $\eta_{\text {charger }}$ is the efficiency of the charger, or efficiency of line AC to charge batteries, with a value of 0.93 . In regulation-down only mode, theoretical research assumes that $D o D$ is $50 \%$ at the start so after the battery is fully charged, the vehicle will not be available to provide regulation down.

Using Equations (2)-(4) and the cost of purchased electricity of $€ 0.066 / \mathrm{kWh}$, theoretical research calculates the cost of energy for regulation $\left(c_{e n}\right)$, which is $€ 0.235 / \mathrm{kWh}$.

Theoretical research calculates that each forklift of the fleet would be plugged in for 8.43 hours $\left(t_{\text {plug }}\right)$ and DoD 
would be $80 \%$, which means that each forklift could miss out on $20 \%$ of the energy stored in the battery. Based on that research we can calculate the annual revenue of each forklift using Equation (8):

$$
r_{\text {Reg-up }}=\left(p_{\text {cap }} P t_{\text {plug }}\right)+\left(p_{e l} P t_{\text {plug }} R_{d-c}\right)
$$

where the $p_{\text {cap }}$ is the capacity price in $€ / \mathrm{kWh}, t_{\text {plug }}$ the amount of time in hours the forklift is plugged in, $p_{e l}$ the market (selling) price of electricity $(€ / \mathrm{kWh})$ and $\mathrm{P}$ is the power of the forklift in $\mathrm{kW}$.

The term $\left(R_{d-c}\right)$ is the dispatch to contract ratio, which in combination with $t_{\text {plug }}$ defines the dispatch of F2G power [3]. The $R_{d-c}$ is defined by Equation (9):

$$
R_{d-c}=\frac{E_{\text {disp }}}{P_{\text {cont }} t_{\text {cont }}}=\frac{E_{\text {disp }}}{P t_{\text {plug }}}
$$

where $E_{\text {disp }}$ is the energy of the battery in $\mathrm{kWh}, P$ is the power of the forklift motor in $\mathrm{kW}$ and $t_{\text {plug }}$ is the time in hours that forklift is plugged in.

\subsection{Results and Discussion}

If implementation of the business model (Figure 5) is split into two parts and we first take a look at the economic viability of solar energy implementation in the energy storage management, we find that the investment in solar power is very profitable and would amount to $€$ 192,000 to the phase of operation. The net present value would be (at a $6 \%$ discount rate, calculated based on a time period of ten years), positive, and the return on investment is expected in nine years. It follows that the implementation of solar power project in the energy storage management certainly economical.

The second part of the business model represents the implemetation of the F2G concept, where a single, initial investment into the upgrade of electric forklifts was $€$ 49,920 . When calculating the net present value, the discount rate was increased in comparison to solar power and was in our case $10 \%$, mainly due to the fact that it is a research project with a correspondingly higher risk. The net present value, which we calculated for the time period of ten years, would be positive and return on investment would be achieved after the first year of forklift operation based on the F2G concept. From that, as with solar power, it follows that the implementation the F2G concept in energy management and storage is economical feasible.

If we look at the overall profitability of the business model (we are talking about the optimistic scenario) with a total investment of $€ 241,920$, then we find that the net present value, calculated for the time period of ten (10) years, was also positive and that the investment would already be repaid in third year of operation of the business model (Figure 6). For comparison and credibility of

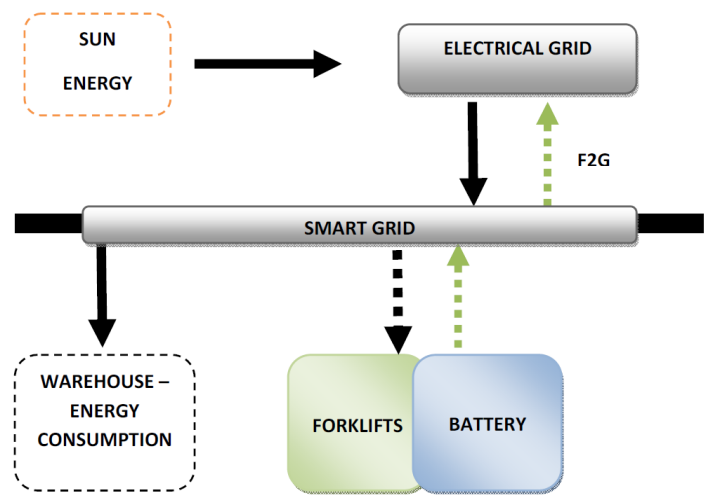

Figure 5. Model of F2G implementation in warehouse.

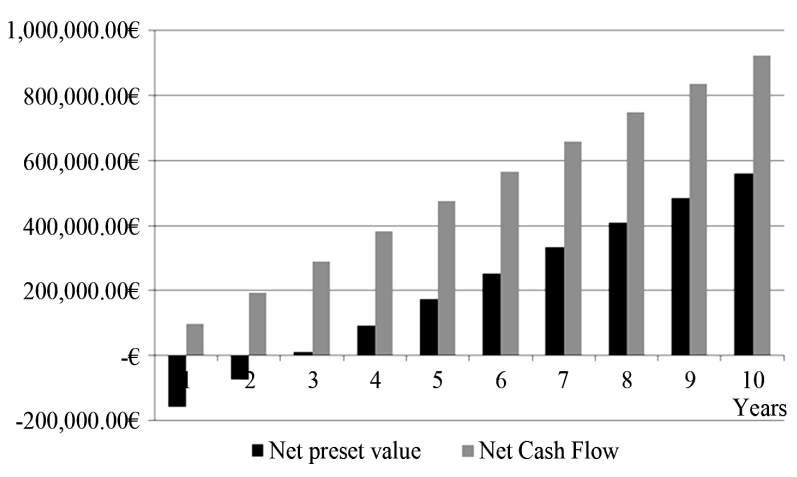

Figure 6. NPV and NCF of our proposed business model.

the proposed model, we selected different prices of electricity, which we sell to the grid and even at lower purchase prices the investment in our model would still be reimbursed in less than ten years.

The annual energy costs of the warehouse are just over $€ 200,000$. With the implementation of our innovative business model, according to the net cash flow, the average cost of electricity, calculated for a period of ten years, decreased by approximately $43 \%$. Based on this we can determine and conclude that the implementation of the business model is profitable, feasible and very promising for the company, which would particularly be felt on the revenue side of the business - net cash flow calculated on a ten-year average would have amounted to $€ 92.341$ per year.

According to the last result, theoretical research can also argue that by purchasing less electrical energy from the grid, the energy system is becoming friendlier to the environment, because it reduces the carbon dioxide footprint. One $\mathrm{kWh}$ of electrical energy in Slovenia is equal to $0.618 \mathrm{~kg} \mathrm{CO}_{2}$, what in theory means approx. 10 tons $(-4.6 \%)$ of $\mathrm{CO}_{2}$ less in summer time (per month) and 1 ton $(-0.5 \%)$ in winter time (per month).

It should be noted that this concept is still unfamiliar in Slovenia and comes from the US, where it has already been successfully integrated to the local power network [12]. A similar case or similar studies, where 
they tried to integrate the batteries of electric forklifts into the electricity grid in similar manner as shown in the article could not be found anywhere else, so we believe that the present article is the first one to deal with such a method of forklift integration, in Slovenia, as well as worldwide.

\section{Conclusions}

In this study we have not dealt with the implementation in practice, whether the organization produces and sells electricity, and with questions regarding the registration of additional activities. Everything was focused on the theoretical concept, but in practice the idea has some limitations that we are describing further below. Despite some limitations, the business model is definitely innovative and economically viable, and with further technological development of batteries it will soon be suitable for practical implementation.

The result is a quantitative understanding of how electric forklifts can become a part of the electrical grid. Our conclusion is that the described F2G model of implementation of electric forklifts into warehouse energy management probably will not generate enormous amounts of power, but it will provide additional storage and back-up the national grid when it will be needed.

We are aware of the fact that the technical side includes limitations, such as: the current batteries of forklifts are not designed for use together with the F2G concept, battery cycles should be higher, regulation signal from the national grid is also a problem; smart grids must be implemented into this kind of electrical systems, not just on the national level but also on the local (company) level, there are no standards and national laws for F2G and no mass production of the equipment needed for this technology.

From the perspective of the electric power, the study shows that F2G could become a new power source, which will play an important role in energy management and will also affect costs of logistics operations in warehouses. The forklift won't be just a machine for loading and unloading, but also a battery for renewable energy sources and a new power source for the local (company) or national grid.

\section{REFERENCES}

[1] T. Muneer, M. Asif and S. Munawwar, "Sustainable ProDuction of Solar Electricity with Particular Reference to the Indian Economy," Renewable and Sustainable Energy
Reviews, Vol. 9, No. 5, 2005, pp. 444-473. doi:10.1016/j.rser.2004.03.004

[2] ELEKTRO SLOVENIJA d.o.o., "The Generation Adequacy and Sufficiency of Electricity Transmission Network in the Republic of Slovenia for the Period 20072011," ELES, Ljubljana, 2007.

[3] J. Tomić and W. Kempton, "Using Fleets of ElectricDrive Vehicles for Grid Support," Journal of Power Sources, Vol. 168, No. 2, 2007, pp. 459-468. doi:10.1016/j.jpowsour.2007.03.010

[4] J. Rydzewski, "V2G-101: A Text about Vehicle-to-Grid, the Technology Which Enables a Future of Clean and Efficient Electric-Powered Transportation," Foreword for Energy Transfer System for Electric Vehicles, United States, BookSurge Publishing, Charleston, 2009, pp. 4445.

[5] W. Kempton, J. Tomić, S. Letendre, A. Brooks and T. Lipman, "Vehicle to Grid Power: Battery, Hybrid, and Fuel Cell Vehicles as Resources for Distributed Electric Power in California," California Air Resources Board and the California Environmental Protection Agency and Los Angeles Department of Water Power, Electric Transportation Program, Los Angeles, 2001.

[6] W. Kempton and J. Tomić, "Vehicle-to-Grid Power Implementation: From Stabilizing the Grid to Supporting LargeScale Renewable Energy," Journal of Power Sources, Vol. 144, No. 1, 2005, pp. 280-294. doi:10.1016/i.jpowsour.2004.12.022

[7] R. Morrison, "The Future Is Now: Grid-Tied Electric Vehicles (Going GREEN)," New Hampshire Business Review, 9 May 2008.

[8] M. Knez and P. Bajor, "A Concept of Solar WarehouseCase of Slovenia's Biggest Retailer Mercator," International Scientifically-Practical Conference Devoted to 50th Anniversary of the Siberian State Aerospace University, Named after Academician M. F. Reshetnev, Krasnoyarsk, 4-5 February 2010, pp. 34-41.

[9] Enecon, "Solar Power Station on My Roof," Guidelines for Planning of Photovoltaic's Systems for Production of Electrical Energy, Enecon, Ljubljana, 2009.

[10] B. Jereb and M. Knez, "Cost-Effectiveness of a Photovoltaic System," Proceedings of the 7th International Conference on Logistics \& Sustainable Transport, Celje, 1415 June 2010, pp. 67-75.

[11] AC Propulsion, "AC-150 Gen-2 EV Power System: Integrated Drive and Charging for Electric Vehicles," 2007. http://www.acpropulsion.com/technology/gen2.htm

[12] L. O. Evans, "Wehicle to Grid Technology: Electric Cars Become Power Grid Batteries," 2011.

http://blogs.scientificamerican.com/guest-blog/2011/10/2 7/vehicle-to-grid-technology-electric-cars-become-powergrid-batteries 